\title{
Decision support system for tool condition monitoring in milling process using artificial neural network
}

\author{
T. Mohanraj* and A. Tamilvanan** \\ *Department of Mechanical Engineering, Amrita School of Engineering, Coimbatore, Amrita Vishwa Vidyapeetham, India \\ **Department of Mechanical Engineering, Kongu Engineering College, Erode \\ *Corresponding Author:_tmohanraj@cb.amrita.edu
}

Submitted :03/02/2020

Revised : 29/07/2021

Accepted :09/08/2021

\begin{abstract}
This work discusses the development of tool condition monitoring system (TCMs) during milling of AISI stainless steel 304 using sound pressure and vibration signals. Response Surface Methodology (RSM) was used to design the experiments. The various milling parameters and vegetable-based cutting fluids (VBCFs) were optimized to reduce the surface roughness and flank wear. The experimental results reveal the direct relationship between the flank wear and sound and vibration signals. The various statistical parameters were extracted from the measured signals and given as input data to train the artificial neural network (ANN). From the developed ANN model, the flank wear was predicted with the mean squared error (MSE) of $0.0656 \mathrm{~mm}$.
\end{abstract}

Keywords: Stainless steel 304; Milling process; Response surface methodology; Surface roughness; Flank wear; Sound pressure; Vibration signals; Tool condition monitoring system.

\section{INTRODUCTION}

Tool wear prediction and replacement depend on traditional calculation of wear data from the past years. To fabricate good quality products with minimal cost, a Tool Condition Monitoring system (TCMs) is necessary. The tool condition has been monitored with various sensors called as sensor fusion model (Dimla, 2000). The TCMs were developed with various features taken out from machining force, cutting sound, spindle vibration, and current signals. The extracted features were combined to calculate the flank wear (Ghosh et al., 2007). Online TCMs were designed using Support Vector Machine (SVM) with statistical features of cutting force, torque, AE, and vibration signals. The tool condition was estimated from the SVM results (Kaya et al., 2012). TCMs were designed using SVM with wavelet features of AE and sound signal and attained better classification accuracy (Zhang et al., 2015).

Different clustering methods were applied for online TCM. The wavelet features were extracted from AE, cutting force, and vibration signals and found the enhanced performance of fuzzy clustering than other methods (Torabi et al., 2016). Recently, during milling process, tool wear was supervised with cutting force, cutting sound, spindle motor current, and vibration signals. The sensor signals were combined together in FIS, and the tool condition was assessed and reached a conclusion to change the tool/machining conditions (Cuka and Kim, 2017). The various 
decision making algorithms were used to forecast the surface roughness and wear (Shankar et al., 2019b). A review of TCMs was discussed by Mohanraj et al. (2020).

Vegetable based cutting fluids (VBCFs) are environment-friendly, inexhaustible, and harmless. The destructive effects of commercial cutting fluids (CFs) can be significantly reduced by employing VBCFs as CFs (Alves and de Oliveira, 2006). Vegetable-oil-based hybrid nano-CFs were developed with the nano-additives (CNT/MoS 2$)$ with

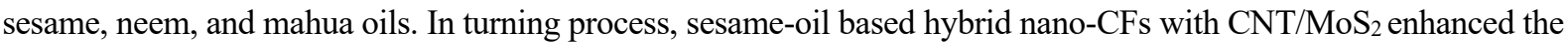
machining performance in terms of flank wear, surface roughness, cutting force, and temperature compared to dry and commercial CF (Pasam and Gugulothu, 2018).

During machining of TC4 alloy, nano-graphene-scattered VBCF (LB 2000) considerably reduces the cutting force, cutting temperature, surface roughness, and surface micro-hardness (Li et al., 2019, Li et al., 2018). Various VBCFs were used for milling the Al 7075-T6 composite and observed that castor oil was performed better than other oils in terms of reduction in flak wear (Mohanraj et al., 2019).

TCMs were designed using various sensors and commercial cutting fluids. The development of TCMs for milling of Stainless Steel (SS) 304 with VBCFs was rarely found in the literature. The VBCFs appreciably decrease the wear and vibration during the milling process. The objective of this work is to develop the TCMs to monitor the tool condition with VBCFs as a CF for milling of SS 304 with cutting sound and vibration signals.

\section{MATERIALS AND METHODS}

The keyway milling experiment was conducted on LMill-55 CNC vertical machining center (Make: LMW, Coimbatore). The SS $304(50 \mathrm{~mm} \times 50 \mathrm{~mm} \times 100 \mathrm{~mm})$ was considered a workpiece, and milling experiments were performed with three-flute TiN coated cemented carbide insert (XDHT-090308 HX-PA 120) of $\phi 25 \mathrm{~mm}$ cutter. Figure 1 shows the milling setup used for this work.

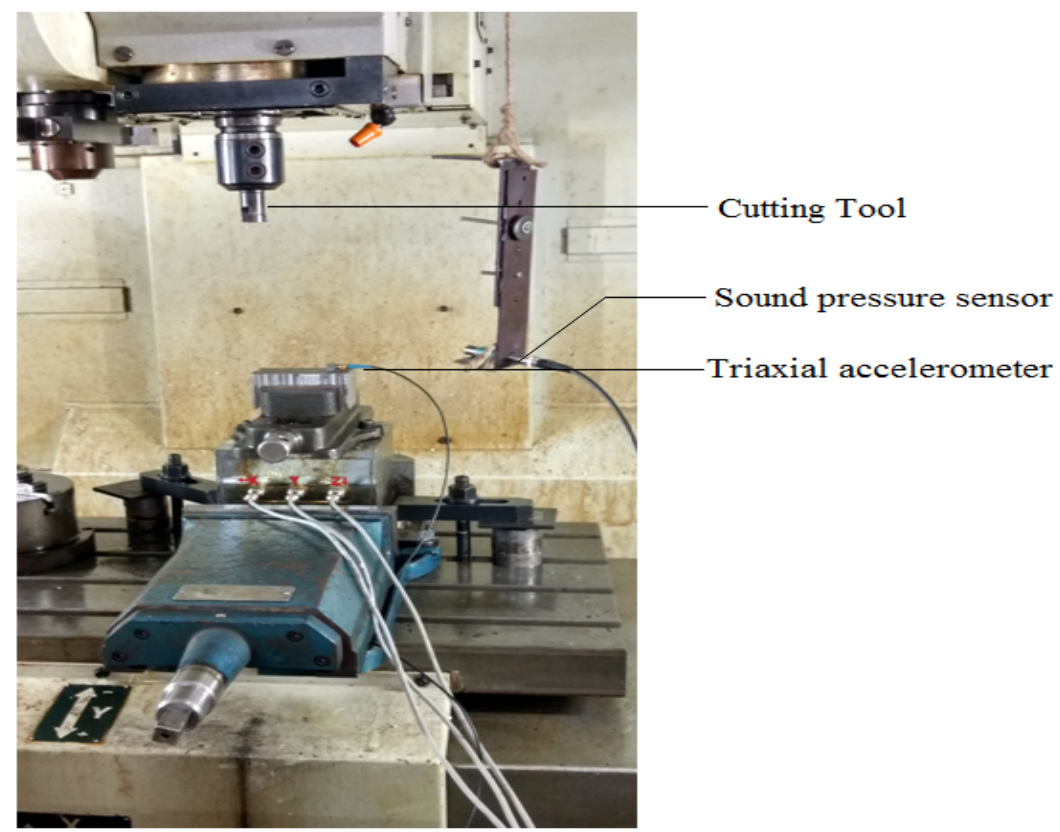

Figure 1. Experimental setup. 
The control parameters, namely, spindle speed, feed rate, and depth of cut with three levels, were considered. The experimental design matrix was developed using response surface methodology (RSM) (Gur et al., 2020). The surface roughness and flank wear were assessed with surface roughness tester SJ-410 and Tool Makers' Microscope, respectively. The design matrix along with experimental results was presented in Table 1.

Table 1. Experimental design.

\begin{tabular}{|c|c|c|c|c|c|}
\hline Exp. No. & $\begin{array}{l}\text { Spindle speed } \\
\text { (A) }(\text { rpm })\end{array}$ & $\begin{array}{c}\text { Feed } \\
\text { (B) }\left(m m . r e v^{-1}\right)\end{array}$ & $\begin{array}{l}\text { Depth } \\
\text { (C) }(\mathrm{mm})\end{array}$ & $\begin{array}{c}\text { Surface } \\
\text { roughness }(\mu m)\end{array}$ & $\begin{array}{l}\text { Flank wear } \\
(\mathrm{mm})\end{array}$ \\
\hline 1 & 750 & 0.48 & 1.00 & 0.88 & 0.0298 \\
\hline 2 & 1000 & 0.48 & 0.75 & 0.682 & 0.0332 \\
\hline 3 & 750 & 1.18 & 0.75 & 0.844 & 0.0331 \\
\hline 4 & 750 & 0.48 & 0.75 & 0.789 & 0.0325 \\
\hline 5 & 899 & 0.90 & 0.90 & 0.911 & 0.0322 \\
\hline 6 & 750 & 0.48 & 0.75 & 0.689 & 0.0321 \\
\hline 7 & 750 & 0.48 & 0.75 & 0.753 & 0.0322 \\
\hline 8 & 601 & 0.90 & 0.90 & 1.102 & 0.0328 \\
\hline 9 & 899 & 0.06 & 0.60 & 0.75 & 0.0352 \\
\hline 10 & 899 & 0.06 & 0.90 & 0.3703 & 0.0326 \\
\hline 11 & 500 & 0.48 & 0.75 & 0.600 & 0.0324 \\
\hline 12 & 601 & 0.90 & 0.60 & 0.528 & 0.0351 \\
\hline 13 & 750 & 0.23 & 0.75 & 0.565 & 0.0334 \\
\hline 14 & 750 & 0.48 & 0.75 & 0.651 & 0.0310 \\
\hline 15 & 750 & 0.48 & 0.75 & 0.656 & 0.0333 \\
\hline 16 & 750 & 0.48 & 0.50 & 0.839 & 0.0338 \\
\hline 17 & 601 & 0.06 & 0.60 & 0.471 & 0.0351 \\
\hline 18 & 750 & 0.48 & 0.75 & 0.661 & 0.0312 \\
\hline 19 & 601 & 0.06 & 0.90 & 0.431 & 0.0271 \\
\hline 20 & 899 & 0.90 & 0.60 & 0.633 & 0.0277 \\
\hline
\end{tabular}


The instruments used for measuring the surface roughness and flank wear were given in Figure 2. First, the commercial cutting fluid was used, and the milling parameters were adjusted to reduce the surface roughness and flank wear. Later, the milling process was performed with optimum condition and VBCFs such as neem, cotton seed, castor, palm, groundnut, and rapeseed. For each VBCF, the experiments were replicated for three times, and the results were obtained. The $\mathrm{CF}$, which enhances the surface quality and tool life, was selected. Finally, the milling process was performed with selected $\mathrm{VBCF}$ and optimum condition to measure the vibration ( $\mathrm{g}$ ) and sound pressure (Pa) signals. The different tool conditions like fresh, working, and dull were chosen.

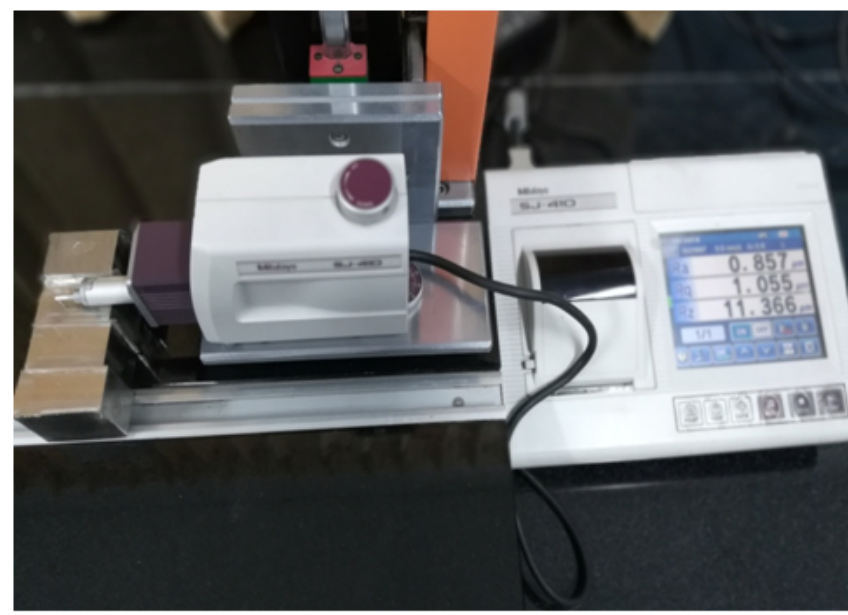

a

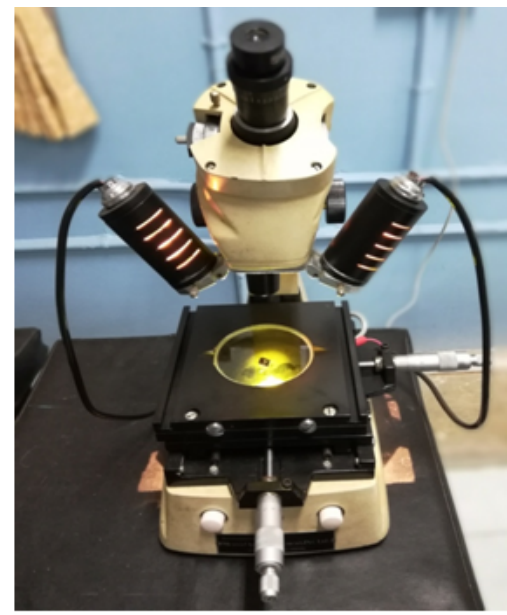

$\mathrm{b}$

Figure 2. a) Measurement of surface roughness. b) Flank wear.

Sound pressure $(\mathrm{Pa})$ and workpiece vibration $(\mathrm{g})$ signals were measured using a Microphone (Make: GRAS) and a Tri-axial accelerometer (Make: Dytran) in that order. The microphone was mounted at a distance of $30 \mathrm{~cm}$ from cutting zone to measure the sound pressure signal and safeguard the sensor from coolant. The signals were acquired using NI 9274 data acquisition card, and the obtained signals were processed using LabVIEW software.

\section{RESULTS AND DISCUSSION}

\section{Analysis for Surface Roughness}

Analysis of variance (ANOVA) is used to identify the most significant process parameters (Gür, 2013). ANOVA for surface roughness was shown in Table 2. The main effect of feed (B) (Shankar et al., 2016, Subramaniam and Thangamuthu, 2017), two-level interaction of feed, and depth (BC) were the most considerable terms for surface roughness. Additionally, two-level interaction of spindle speed and depth (AC), second-order term of feed $\left(\mathrm{B}^{2}\right)$, and depth $\left(\mathrm{C}^{2}\right)$ were found as substantial. Feed rate had the maximum percentage contribution of $38.2 \%$, and it had physical significance. Previous work (Sahin and Motorcu, 2005, Vikrama et al., 2015, Khorasani and Yazdi, 2015, Zhang et al., 2016) reported that the feed was deciding factor for surface quality. The spindle speed and depth had very less impact on surface roughness. The same effect of depth of cut was found in milling of $\mathrm{AA} 7039 / \mathrm{Al}_{2} \mathrm{O}_{3}$ composites (Karabulut, 2015). 
Table 2. Analysis for surface roughness.

\begin{tabular}{|c|c|c|c|c|c|c|}
\hline Source & $\begin{array}{l}\text { Sum of } \\
\text { squares }\end{array}$ & $\mathrm{df}$ & Mean Square & F Value & $\begin{array}{l}\text { p-Value } \\
\text { Prob }>F\end{array}$ & $\%$ Contribution \\
\hline Model & 0.5623 & 9 & 0.0624 & 21.06 & $<0.0001$ & -- \\
\hline A & 0.0053 & 1 & 0.0053 & 1.801 & 0.2092 & 0.90 \\
\hline B & 0.2261 & 1 & 0.2261 & 76.232 & $<0.0001$ & 38.21 \\
\hline $\mathrm{C}$ & 0.0183 & 1 & 0.0183 & 6.200 & 0.0320 & 3.11 \\
\hline $\mathrm{AB}$ & 0.0115 & 1 & 0.0115 & 3.90 & 0.0765 & 1.96 \\
\hline $\mathrm{AC}$ & 0.0505 & 1 & 0.0505 & 17.02 & 0.0021 & 8.53 \\
\hline $\mathrm{BC}$ & 0.2021 & 1 & 0.2021 & 68.128 & $<0.0001$ & 34.15 \\
\hline $\mathrm{A}^{2}$ & 0.0109 & 1 & 0.0109 & 3.706 & 0.0831 & 1.86 \\
\hline $\mathrm{B}^{2}$ & 0.0264 & 1 & 0.0264 & 8.913 & 0.0137 & 4.47 \\
\hline $\mathrm{C}^{2}$ & 0.0356 & 1 & 0.0356 & 12.002 & 0.0061 & 6.02 \\
\hline Residual & 0.0296 & 10 & 0.0029 & & & \\
\hline Lack of Fit & 0.0129 & 5 & 0.0025 & 0.776 & 0.6063 & \\
\hline Pure Error & 0.0167 & 5 & 0.0033 & & & \\
\hline Cor. Total & 0.5920 & 19 & & & & \\
\hline
\end{tabular}

\section{Analysis for Wear}

ANOVA result for wear $(\mathrm{Vb})$ is presented in Table 3. Depth $(\mathrm{C})$, effect of speed and feed $(\mathrm{AB})$, effect of feed and depth (BC), and effect of speed and depth (AC) were found as considerable cutting parameters for $\mathrm{Vb}$. Flank wear is dependent on interaction effect of spindle speed and feed (AB). Here, the combined effect of spindle speed and feed had the highest percentage of 25.20 complied by the combined effect of BC that had $22.69 \%$. The influence of spindle speed and depth (AC) had $20.53 \%$ contribution. The depth (C) had significant contribution of $21.44 \%$. The result of spindle speed and feed alone does not have any statistical significance on flank wear (Kaya et al., 2012). From the literature, the most significant parameters for flank wear were A, B, A², and B² (Arokiadass et al., 2012). 
Table 3. Analysis for flank wear.

\begin{tabular}{|c|c|c|c|c|c|c|}
\hline Source & Sum of squares & df & Mean Square & F Value & $\begin{array}{l}\text { p-Value } \\
\text { Prob }>F\end{array}$ & $\%$ Contribution \\
\hline Model & $8.26 \times 10^{-5}$ & 6 & $1.38 \times 10^{-5}$ & 21.234 & $<0.0001$ & -- \\
\hline A & $6.10 \times 10^{-7}$ & 1 & $6.1 \times 10^{-7}$ & 0.9404 & 0.3499 & 0.67 \\
\hline $\mathrm{B}$ & $1.87 \times 10^{-7}$ & 1 & $1.87 \times 10^{-7}$ & 0.2889 & 0.6000 & 0.21 \\
\hline $\mathrm{C}$ & $1.95 \times 10^{-5}$ & 1 & $1.95 \times 10^{-5}$ & 30.1077 & 0.0001 & 21.44 \\
\hline $\mathrm{AB}$ & $2.29 \times 10^{-5}$ & 1 & $2.29 \times 10^{-5}$ & 35.3905 & $<0.0001$ & 25.20 \\
\hline $\mathrm{AC}$ & $1.87 \times 10^{-5}$ & 1 & $1.87 \times 10^{-5}$ & 28.8203 & 0.0001 & 20.53 \\
\hline $\mathrm{BC}$ & $2.07 \times 10^{-5}$ & 1 & $2.06 \times 10^{-5}$ & 31.8573 & $<0.0001$ & 22.69 \\
\hline Residual & $8.43 \times 10^{-6}$ & 13 & $6.48 \times 10^{-7}$ & & & \\
\hline Lack of Fit & $4.84 \times 10^{-6}$ & 8 & $6.05 \times 10^{-7}$ & 0.8425 & 0.6060 & \\
\hline Pure Error & $3.59 \times 10^{-6}$ & 5 & $7.18 \times 10^{-7}$ & & & \\
\hline Cor. Total & $9.10 \times 10^{-5}$ & 19 & & & & \\
\hline
\end{tabular}

\section{Optimization of Milling Parameters}

The optimal milling parameters for machining AISI SS 304 within the chosen range of milling parameters were found, which minimize the surface roughness $(\mathrm{Ra})$ and flank wear $(\mathrm{Vb})$ during milling process. The RSM desirability function was utilized to optimize the process parameters. The numerical optimization was utilized to find the points, which maximize the desirability function. From RSM optimization, a speed of $601 \mathrm{rpm}$, a feed rate of $0.06 \mathrm{~mm}$. $\mathrm{rev}^{-}$ ${ }^{1}$, and a depth of $0.88 \mathrm{~mm}$ were identified as optimal process parameters for machining AISI stainless steel 304. The verification trial was performed, with obtained optimum condition and experimental values being compared with predicted values. The result was given in Table 4.

Table 4. Confirmation test results.

\begin{tabular}{|c|c|c|c|c|c|}
\hline \multicolumn{3}{|c|}{ Surface roughness $(\mu m)$} & \multicolumn{3}{c|}{ Flank wear $(\mathrm{mm})$} \\
\hline Experiment & Prediction & \% Error & Experiment & Prediction & \% Error \\
\hline 0.4325 & 0.4206 & 2.75 & 0.0281 & 0.0271 & 3.55 \\
\hline
\end{tabular}


After finding the optimum condition, the VBCFs were used a CF, and the milling process was conducted thrice. The flank wear was recorded, and the average value was used to select the CF. Table 5 presents the flank wear details for different VBCFs. High viscosity of VBCFs ensured more stable lubrication across the process temperature range, reduced the cutting zone temperature, and formed a thin layer. This behavior of VBCFs reduces friction between workpiece and tool, which leads to possible reduction of heat produced at tool-workpiece interface. The strong intermolecular interactions provide a more stable viscosity and are also flexible to changes in temperature (Gerpen et al., 2004). Moreover, the viscosity of castor oil is more than other VBCFs. This reduced the friction among tool and workpiece and easily removed the heat generated at tool-workpiece interface. During machining process, castor oil exhibits least wear and roughness compared to other VBCFs. So, castor oil exhibits better performance than other VBCFs and is selected as a CF for design of TCMs.

\section{DESIGN OF TCMS FOR AISI STAINLESS STEEL 304}

\section{Effect of Flank Wear on Sound Signal}

The acquired sound pressure signal during machining with different cutting tool is shown in Figure 3. The maximum value of sound produced for worn tool was $6 \mathrm{~Pa}$. The stainless steel 304 was one of the difficult-to-cut materials, and the presence of harder particles may be the reason for the higher amplitude of sound pressure. Figure 3 shows that the raise in flank wear leads to a raise in sound pressure. Once the tool lost its effective cutting edge, tool-work part contact area was increased and not capable of manufacturing the superiority products. The similar tendency was noticed in literatures Kopač and Šali (2001), Ghosh et al. (2007), and Raja et al. (2013).

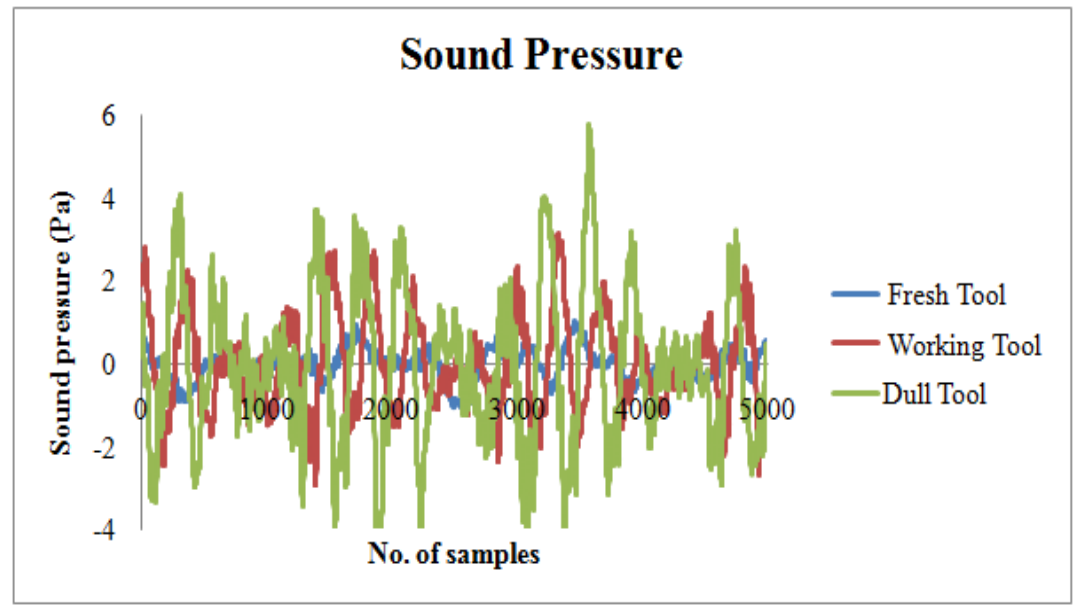

Figure 3. Sound pressure values for different tools.

The sound value for various tool condition clearly illustrated that the sound for dull tool was higher than that of the other two tools. While the cutting tool turns faulty, it augments the contact region and nose radius. At that moment, extra area was in contact with milling surface. That leads to elevating the sound level. The variation in milling parameter and incidence of any fault (breakage, built up edge) should alter the level of sound pressure (Tekıner and Yeşılyurt, 2004). The initial cutting sound was little high owing to initial interaction of cutting tool and workpiece. In dull tool, the contact area was increased due to the increase in flank wear, and it produced the maximum sound pressure (Shankar et al., 2019a). 


\section{Effect of Flank Wear on Vibration Signals}

The resultant vibration for different tools was presented in Figure 4. To analyze the consequence of all threeaxis vibration, the resultant vibration was considered. The vibration in $\mathrm{Y}$ axis had a significant effect since it was the feed direction of the machine. The new tool had a least resultant vibration in the range of $0-3 \mathrm{~g}$. During the early phase of machining, the tool is sharp, and there is only interaction between the nose radius and work part. So, vibration was lesser than that of other tools (Mohanraj and Shanmugam, 2021).

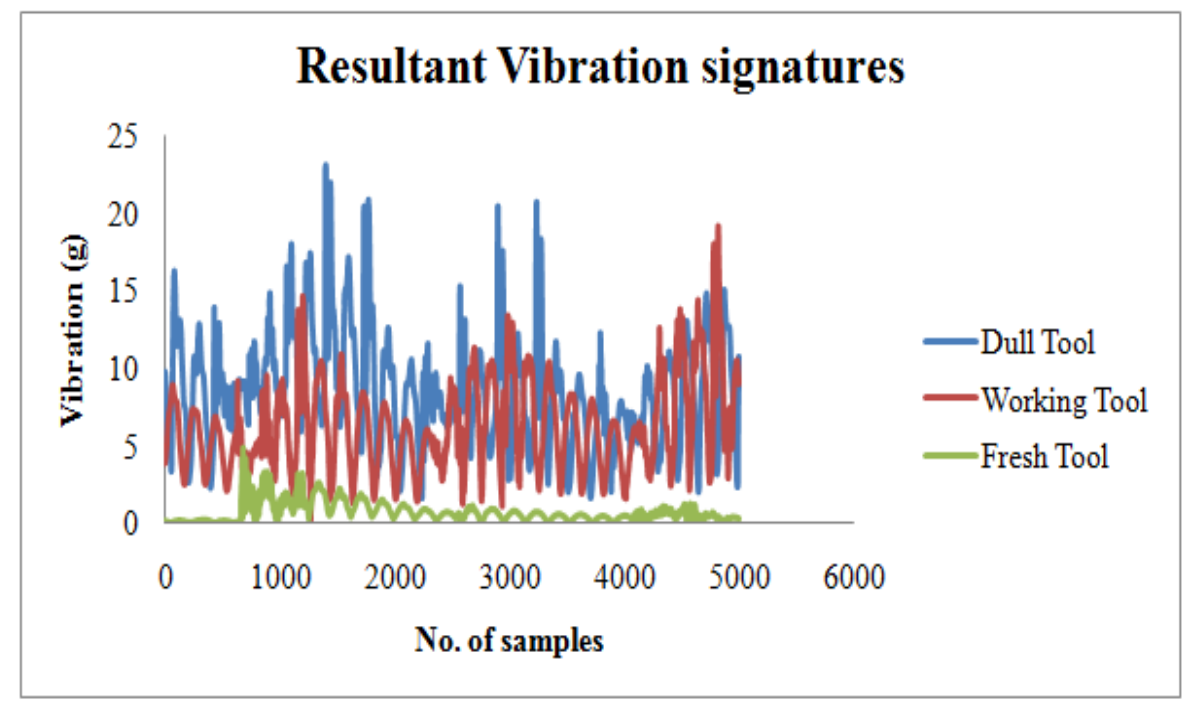

Figure 4. Resultant vibration signatures for different tools.

When the tool crosses the primary wear stage, the tool wear land increased very minimally and maintained uniform contact between tool and work part. So, the identical vibration was continued. The dull tool lost its effective cutting edge, which enlarged the tool-workpiece contact area, and friction results in elevation of vibration. During machining of Inconel 625 (Shankar et al., 2019a, Krishnakumar et al., 2015), the similar trend was noticed. From the above figures, it is evident that the raise in flank wear leads to a raise in vibration. The same trend was found in literatures Chelladurai et al. (2008), Orhan et al. (2007), Dimla and Lister (2000), Pai and D'Mello (2015), and Mohanraj et al. (2021a). The optical image for the fresh and dull tool is shown in Figure 5.

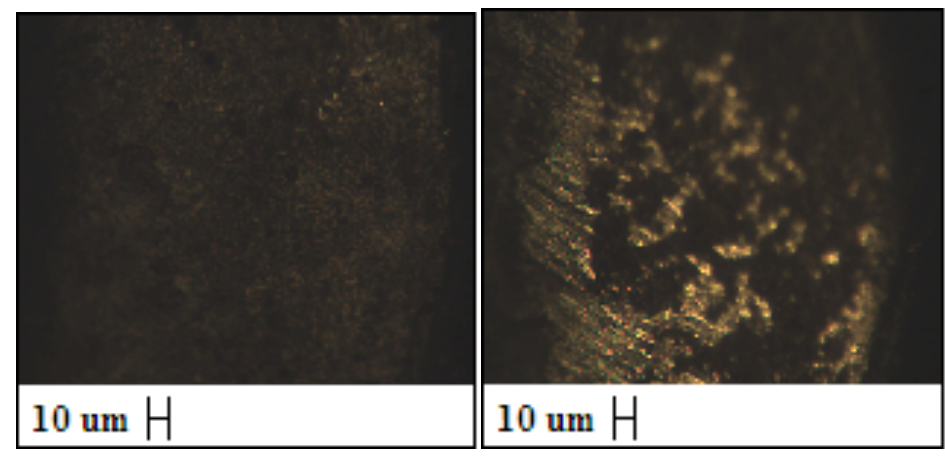

Figure 5. Optical image of the cutting tool. (a) New tool. (b) Dull tool. 


\section{Design and Development of TCMs using ANN}

The widely used Backpropagation Neural Network (BPNN) was employed for estimating the tool condition in milling process. The advantages of using BPNN algorithm are the ability to model, estimate mathematically, and match the nonlinear model (Taskin et al., 2008). The statistical parameters like RMS, kurtosis, skewness, and mean of sound pressure and the resultant vibration were used as inputs for $\mathrm{NN}$ predictor. The flank wear was considered as the output data, and it was given as target. The TRAINLM (Levenberg-Marquardt backpropagation) function was selected as NN training function. Learning and performance functions of LEARNGDM (gradient descent momentum weight/bias learning function) and Mean Squared Error (MSE) were considered, respectively. TANSIG (hyperbolic tangent sigmoid) transfer function was employed to estimate the output from its network input.

The number of hidden nodes was started with 10 and gradually increased up to 30 to obtain the optimal performance. The number of iterations was set as 1000 . The training process started with the above said initial conditions. The best performance was obtained at $5^{\text {th }}$ iteration with the best validation performance of $0.0656 \mathrm{~mm}$ MSE. Figure 6 shows performance graph of the developed NN estimator. The $75 \%$ of data (1050 samples) were utilized for training purposes, and $25 \%$ (450 samples) were used for testing and validation purposes (Mohanraj et al., 2021b). The lower value of MSE provides better performance.

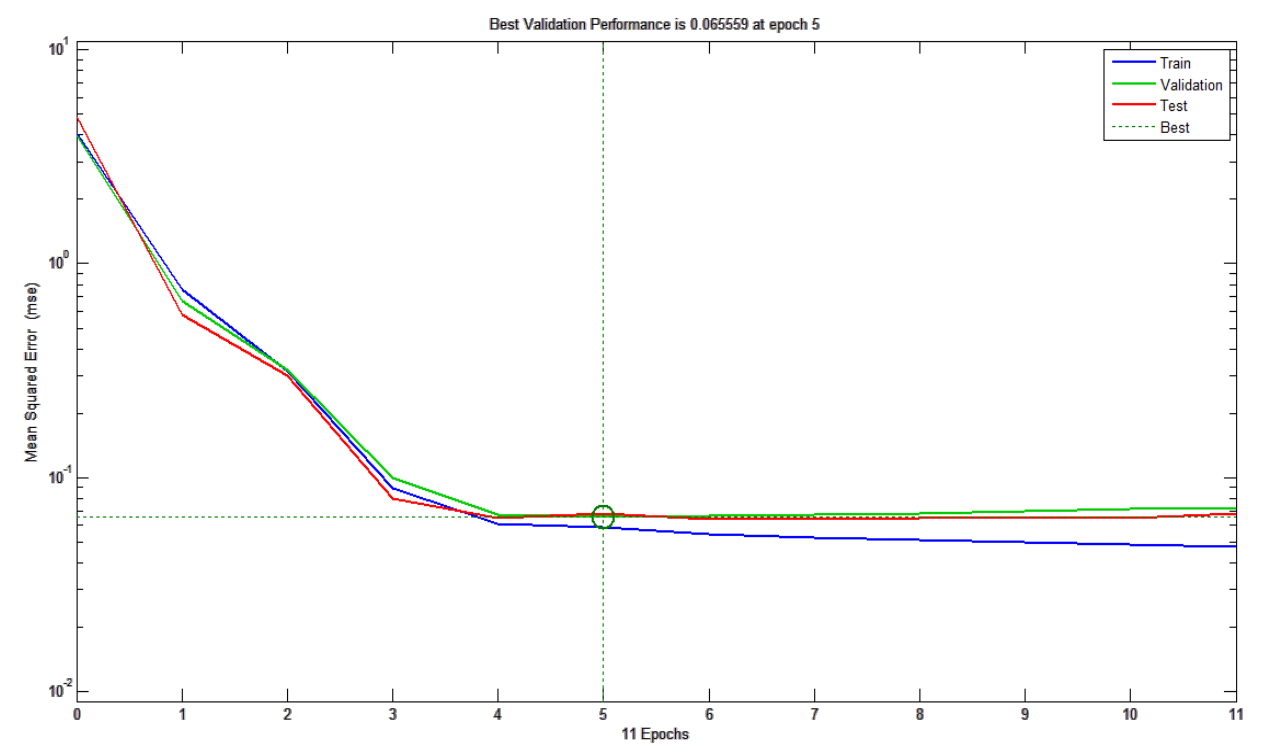

Figure 6. ANN performance graph. 

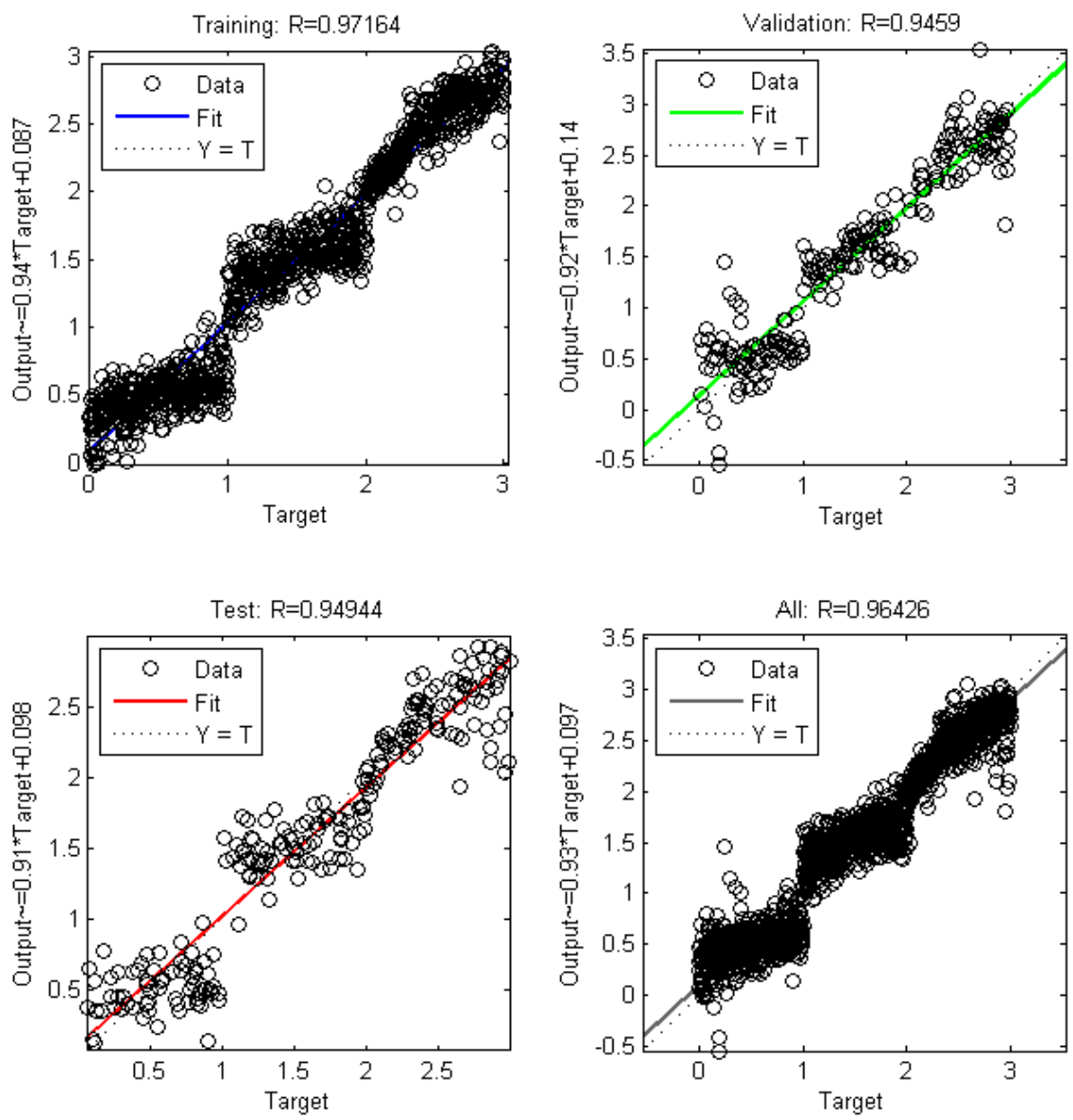

Figure 7. Regression plot.

When MSE is closer to zero, this indicates that the designed estimator has no errors. Here, the designed NN estimator had MSE of $0.0585 \mathrm{~mm}$ during training phase. During testing phase, the NN had MSE of $0.06788 \mathrm{~mm}$. This performance level is satisfied for TCMs application. Further, the prediction accuracy can be enhanced by applying machine learning algorithms (Krishnakumar et al., 2018a, Krishnakumar et al., 2018c, Krishnakumar et al., 2018b).

The regression coefficient for the designed NN estimator was presented in Figure 7. For training phase, testing phase, and validation, the regression coefficient was $0.9716,0.9494$, and 0.9459 , respectively. The overall regression coefficient was 0.9642 . The VBCFs have good friction reduction abilities, and the friction was reduced during toolworkpiece contact, which produced better surface finish. The VBCFs have the capability of creating thin layer, which enhances the boundary lubrication, as a result reducing the friction at tool-workpiece contact zone, which decreases the flank wear. Surface roughness was enhanced slightly, due to the temperature reduction in machining zone (Mohanraj et al., 2019).

The enhancement of friction owing to rise in contact zone generates elevated vibration signals, resulting in raise in amplitude of vibration signals. Beyond the certain level of flank wear, considerable increase in contact area was observed, for the reason of plastic deformation and speeding up of tool wear. The amplitude change of dull tool may be due to the deformation behavior of material in shear zone. When the flank wear increased, it increases the contact 
area between tool and work material. Also, it increases tool nose radius, and the tool becomes dull to remove the material from the workpiece.

\section{CONCLUSION}

The keyway milling experiments were carried out on AISI SS 304, using cemented carbide insert (WIDIA XDHT-090308HX-PA120) for tool wear estimation, and the process was monitored using sound pressure and vibration signals. An effort was geared up to design a simple low-cost TCMs, using sensor fusion technique. The results achieved from the experiment were presented as follows:

- $\quad$ Feed was the most significant factor for surface quality.

- Surface roughness was augmented with raise in feed. Larger feed values augment the temperature and reduce the bonding strength in the work material, which affects the surface quality.

- The temperature at tool-workpiece contact was increased, while speed and depth were increased, which decreases the tool life

- The speed of $601 \mathrm{rpm}$, feed of $0.06 \mathrm{~mm} \cdot \mathrm{rev}^{-1}$, and depth of $0.88 \mathrm{~mm}$ were obtained as optimal process parameters.

- Castor oil exhibits the minimum flank wear. Due to high viscosity, cutting fluid greatly reduces the cutting zone temperature and hence reduces the flank wear.

- The output of NN was accessed to monitor the tool wear. When NN result reaches the value of 3, cutting tool has to be substituted for further operations.

\section{REFERENCES}

Alves, S. M. \& de Oliveira, J. F. G. 2006. Development of new cutting fluid for grinding process adjusting mechanical performance and environmental impact. Journal of materials processing technology, 179: 185-189.

Arokiadass, R., Palaniradja, K. \& Alagumoorthi, N. 2012. Prediction and optimization of end milling process parameters of cast aluminium based MMC. Transactions of Nonferrous Metals Society of China, 22: 1568-1574.

Chelladurai, H., Jain, V. \& Vyas, N. 2008. Development of a cutting tool condition monitoring system for high speed turning operation by vibration and strain analysis. The International Journal of Advanced Manufacturing Technology, 37: 471-485.

Cuka, B. \& Kim, D.-W. 2017. Fuzzy logic based tool condition monitoring for end-milling. Robotics and Computer-Integrated Manufacturing, 47: 22-36.

Dimla, D. \& Lister, P. 2000. On-line metal cutting tool condition monitoring.: I: force and vibration analyses. International Journal of Machine Tools and Manufacture, 40: 739-768.

Dimla, D. E. 2000. Sensor signals for tool-wear monitoring in metal cutting operations - a review of methods. International Journal of Machine Tools and Manufacture, 40: 1073-1098.

Gerpen, J., Shanks, B., Pruszko, R., Clements, D. \& Knothe, G. 2004. Biodiesel Production Technology, August 2002-January 2004 Subcontractor Report. National Renewable Energy Laboratory, Colarado: 22-27. 
Ghosh, N., Ravi, Y., Patra, A., Mukhopadhyay, S., Paul, S., Mohanty, A. \& Chattopadhyay, A. 2007. Estimation of tool wear during CNC milling using neural network-based sensor fusion. Mechanical Systems and Signal Processing, 21: 466-479.

Gür, A. K. 2013. Investigating Wear Behavior By Using Taguchi Method FeCrCB4C Powder Alloys Coating By Plasma Transferred Arc Weld Surfacing. MP-Materials Testing-Materials and Components Technology and Application, 55: 462-467.

Gur, A. K., Ozay, C. n. \& Icen, B. 2020. Evaluation of B4c/Ti coating layer, investigation of abrasive wear behaviors using Taguchi technique and response surface methodology. Surface Review and Letters, 27: 1950225 .

Karabulut, Ş. 2015. Optimization of surface roughness and cutting force during AA7039/Al 2 O 3 metal matrix composites milling using neural networks and Taguchi method. Measurement, 66: 139-149.

Kaya, B., Oysu, C., Ertunc, H. M. \& Ocak, H. 2012. A support vector machine-based online tool condition monitoring for milling using sensor fusion and a genetic algorithm. Proceedings of the Institution of Mechanical Engineers, Part B: Journal of Engineering Manufacture, 226: 1808-1818.

Khorasani, A. \& Yazdi, M. R. S. 2015. Development of a dynamic surface roughness monitoring system based on artificial neural networks (ANN) in milling operation. The International Journal of Advanced Manufacturing Technology: 1-11.

Kopač, J. \& Šali, S. 2001. Tool wear monitoring during the turning process. Journal of Materials Processing Technology, 113: 312-316.

Krishnakumar, P., Rameshkumar, K. \& Ramachandran, K. 2015. Tool wear condition prediction using vibration signals in high speed machining (HSM) of titanium (Ti-6Al-4 V) alloy. Procedia Computer Science, 50: $270-275$.

Krishnakumar, P., Rameshkumar, K. \& Ramachandran, K. 2018a. Acoustic emission-based tool condition classification in a precision high-speed machining of titanium alloy: a machine learning approach. International Journal of Computational Intelligence and Applications, 17: 1850017.

Krishnakumar, P., Rameshkumar, K. \& Ramachandran, K. 2018b. Feature level fusion of vibration and acoustic emission signals in tool condition monitoring using machine learning classifiers. International Journal of Prognostics and Health Management, 9.

Krishnakumar, P., Rameshkumar, K. \& Ramachandran, K. 2018c. Machine learning based tool condition classification using acoustic emission and vibration data in high speed milling process using wavelet features. Intelligent Decision Technologies, 12: 265-282.

Li, M., Yu, T., Yang, L., Li, H., Zhang, R. \& Wang, W. 2019. Parameter optimization during minimum quantity lubrication milling of TC4 alloy with graphene-dispersed vegetable-oil-based cutting fluid. Journal of cleaner production, 209: 1508-1522.

Li, M., Yu, T., Zhang, R., Yang, L., Li, H. \& Wang, W. 2018. MQL milling of TC4 alloy by dispersing graphene into vegetable oil-based cutting fluid. The International Journal of Advanced Manufacturing Technology, 99: 1735-1753. 
Mohanraj, T., Ragav, P., Gokul, E., Senthil, P. \& Anandh, K. R. 2021a. Experimental investigation of coconut oil with nanoboric acid during milling of Inconel 625 using Taguchi-Grey relational analysis. Surface Review and Letters (SRL), 28: 1-11.

Mohanraj, T., Shankar, S., Rajasekar, R., Deivasigamani, R. \& Arunkumar, P. M. 2019. Tool condition monitoring in the milling process with vegetable based cutting fluids using vibration signatures. Materials Testing, 61: 282-288.

Mohanraj, T., Shankar, S., Rajasekar, R., Sakthivel, N. R. \& Pramanik, A. 2020. Tool condition monitoring techniques in milling process - a review. Journal of Materials Research and Technology, 9: 1032-1042.

Mohanraj, T. \& Shanmugam, A. Prediction of tool wear in milling of Inconel 625 using and integrated kurtosisbased algorithm with vibration signals. Journal of Physics: Conference Series, 2021. IOP Publishing: 012048.

Mohanraj, T., Yerchuru, J., Krishnan, H., Aravind, R. N. \& Yameni, R. 2021b. Development of tool condition monitoring system in end milling process using wavelet features and Hoelder's exponent with machine learning algorithms. Measurement, 173: 108671.

Orhan, S., Er, A. O., Camuşcu, N. \& Aslan, E. 2007. Tool wear evaluation by vibration analysis during end milling of AISI D3 cold work tool steel with 35 HRC hardness. NDT \& E International, 40: 121-126.

Pai, P. S. \& D'Mello, G. 2015. Vibration signal analysis for monitoring tool wear in high speed turning of Ti6Al-4V. Indian Journal of Engineering \& Materials Sciences, 22: 652-660.

Pasam, V. K. \& Gugulothu, S. 2018. Testing and Performance Evaluation of Vegetable-Oil-Based Hybrid Nano Cutting Fluids. Journal of Testing and Evaluation, 48.

Raja, J., Kiong, L. \& Soong, L. 2013. Hilbert-Huang Transform-Based Emitted Sound Signal Analysis for Tool Flank Wear Monitoring. Arabian Journal for Science \& Engineering (Springer Science \& Business Media BV), 38.

Sahin, Y. \& Motorcu, A. R. 2005. Surface roughness model for machining mild steel with coated carbide tool. Materials \& design, 26: 321-326.

Shankar, S., Mohanraj, T. \& Pramanik, A. 2019a. Tool Condition Monitoring While Using Vegetable Based Cutting Fluids During Milling of Inconel 625. Journal of Advanced Manufacturing Systems, 18: 561-581.

Shankar, S., Mohanraj, T. \& Rajasekar, R. 2019b. Prediction of cutting tool wear during milling process using artificial intelligence techniques. International Journal of Computer Integrated Manufacturing, 32: 174-182.

Shankar, S., Mohanraj, T. \& Thangarasu, S. K. 2016. Multi-response milling process optimization using the Taguchi method coupled to grey relational analysis. Materials Testing, 58: 462-470.

Subramaniam, S. \& Thangamuthu, M. 2017. Experimental investigation and process parameter optimization in milling of 7075 - T6 hybrid aluminium metal matrix composite using response surface methodology. Journal of the Balkan Tribological Association, 23: 124-138.

Taskin, M., Caligulu, U. \& Gur, A. K. 2008. Modeling adhesive wear resistance of Al-Si-Mg-/SiC p PM compacts fabricated by hot pressing process, by means of ANN. The International Journal of Advanced Manufacturing Technology, 37: 715-721. 
Tekıner, Z. \& Yeşılyurt, S. 2004. Investigation of the cutting parameters depending on process sound during turning of AISI 304 austenitic stainless steel. Materials \& Design, 25: 507-513.

Torabi, A. J., Er, M. J., Li, X., Lim, B. S. \& Peen, G. O. 2016. Application of Clustering Methods for Online Tool Condition Monitoring and Fault Diagnosis in High-Speed Milling Processes. IEEE Systems Journal, 10: 721-732.

Vikrama, K. A., Ratnamb, C., Narayanac, K. S. \& Bend, B. S. 2015. Assessment of surface roughness and MRR while machining brass with HSS tool and carbide inserts. Indian Journal of Engineering \& Materials Sciences, 22: 321-330.

Zhang, C., Li, W., Jiang, P. \& Gu, P. 2016. Experimental investigation and multi-objective optimization approach for low-carbon milling operation of aluminum. Proceedings of the Institution of Mechanical Engineers, Part C: Journal of Mechanical Engineering Science, 231: 2753-2772.

Zhang, K.-f., Yuan, H.-q. \& Nie, P. 2015. A method for tool condition monitoring based on sensor fusion. Journal of Intelligent Manufacturing, 26: 1011-1026. 